This is an author-produced PDF of an article published in International Journal of Music Education. The definitive publisher-authenticated version is available online, copyright Sage Publications. Complete citation information of that definitive version is:

Carey, G., Grant, C., McWilliam, E., \& Taylor, P. (2013). One-to-one pedagogy: Developing a protocol for illuminating the nature of teaching in the conservatoire. International Journal of Music Education 31(2), 148-159. doi: $10.1177 / 0255761413483077$

Retrievable from:

http://journals.sagepub.com/doi/abs/10.1177/0255761413483077

\title{
One-to-one pedagogy: Developing a protocol for illuminating the nature of teaching in the conservatoire
}

\author{
Gemma Carey, Catherine Grant, Erica McWilliam \& Peter Taylor
}

This paper outlines the approach used to develop a scheme to characterize the nature and quality of specific practices of one-to-one teaching, selected on the basis of their potential significance to the development of student performance. Although the value of one-to-one teaching remains largely unchallenged at the conservatoire level, music institutions are increasingly being called to justify the need for such a cost- and resource-intensive pedagogical approach. Funding pressures combined with a lack of systematic investigation into the value and efficacy of one-to-one teaching underscore the urgent need for a rigorous, evidenced-based way to characterize related pedagogical practices. This paper documents the processes of developing one such approach at an Australian conservatoire. The authors hope to encourage and facilitate the implementation of similar projects elsewhere, and thereby help lay the foundation for a systematic and credible international understanding of the value and limitations of one-to-one learning and teaching practices in the conservatoire environment.

Keywords: one-to-one teaching, tertiary music education, pedagogy, systematic inquiry

This paper discusses the development of a rigorous and systematic approach to 'characterizing' one-to-one pedagogical practices within conservatories. The approach characterizes differences in the nature and quality of specific practices, selected on the basis of their potential significance to the development of excellence in teaching and learning. The current discussion focuses on the identification of the actual practices that formed the basis of that characterization. 


\section{Background}

It is nearly two decades since Swedish researcher Roland Persson wrote a critique of 'concert musicians as teachers' (1994) that turned the forensic light of research scrutiny squarely on the 'performer-teacher' in the conservatoire. Persson did so by publishing a research finding that one-to-one teaching in the conservatoire was having a negative impact on students, an effect, he argued, of the tendency of a majority of teacherparticipants to 'dominate their students completely’ (1994, p. 88). Importantly, his study concluded by distinguishing 'formidable artist[s]' from 'formidable pedagogue[s]', not because they are impossible in the one individual but because 'they describe different roles as well as different skills in different contexts' (1994, p. 89, emphasis in original). Two years later, Persson published a further paper (1996b) in which he continued to distinguish commonsense teaching (derived from tradition and lore) from trained or expert teaching (derived from empirical models and knowledge), problematising the former and lauding the latter.

It is possible to situate Persson's papers within a broader imperative for higher education in the mid-1990s to examine pedagogical activity that had hitherto evaded scrutiny, either because of the intimacy and inaccessibility of the space in which it was conducted (for example, doctoral supervision, one-to-one artistic tuition) or because the nexus between rigorous research, pedagogical quality and improved learning outcomes was not yet sufficiently valued or understood. However, all that was about to change. Post-welfare governments began to demand greater accountability for public expenditure on all education-related activities, including those that until then had escaped scrutiny of their efficiency and effectiveness (see Barnett, 1997; Gewirtz, 1999). University teaching and supervisory activities that were deemed both expensive and exclusive, " "scarce" commodit[ies] which we can ill-afford to "waste" ' (Lawson, 1999, p. 11), would now be subject to quality audit, and funded accordingly. Since then, the 'audit explosion' (Strathern, 1997, 2000) has focused attention not only on the local, disciplinary-specific or craft knowledge of higher education teachers as a disciplinary and/or artistic experts, but also on their pedagogical expertise.

In other words, according to the cultural logic of post-welfare public institutions, including the conservatoire, disciplinary or artistic expertise were a necessary but no longer a sufficient condition for being salaried as a university teacher. For this reason, the case for arguing the quality of pedagogical practices in the conservatoire could no longer rely on the untested but widely held assumption that great performer - the 'maestro performer' - would be ipso facto 'the maestro teacher'. A case now had to be made on the basis of evidence, evidence that needed to be both scholarly and credible beyond the confines of any particular conservatoire and its long-held traditions.

This shift in the cultural logic of higher education teaching and learning marked a watershed in pedagogical research, both within and outside the conservatoire. Where previously, few researchers ${ }^{1}$ had taken any real interest in the nature of pedagogical work within the private spaces of one-to-one teaching, it is possible to discern, at the turn of this century, a burgeoning interest in providing evidence-based accounts of the character

\footnotetext{
${ }^{1}$ Some exceptions include Abeles (1975); Brand (1984); Bunting (1987); Gustafson (1986); Kostka (1984); and Schmidt (1989, 1992).
} 
of music education pedagogy. This new generation of inquiry differs from the pre-1990s research both in terms of the greater number of studies being undertaken in various locations throughout the world, and the extent to which these new millennial studies, through their cross-referencing of similar music education research, provide evidence of music pedagogy as a more connected, if still embryonic, focus for scholarship - a field under construction rather than a scattering of relatively unrelated, localized and personalized projects.

One key feature of the shift of music pedagogy research from 'piecemeal' to 'professional' has been the greater interest in, and attention being paid to, the issue of a methodology for interrogating pedagogy itself. For example, in Telling Half the Story: Making Explicit the Significance of Methods and Methodologies in Music Education Research (2006), Pamela Burnard explicitly cautions music education researchers to communicate and discuss the significance of external influences on research design, including the theoretical and conceptual underpinnings of the approach. In similar vein, the work of Kim Burwell (2003; 2005; 2006) foregrounds the importance of the research context as a central rather than a side issue in systematic inquiry into pedagogical practice.

With attention focused more squarely on the relevance of certain emergent research methods, particularly qualitative techniques, for inquiring into music education, it is possible to discern in the first decade of this century a greater interest in probing the still somewhat mysterious field of one-to-one pedagogy in the conservatoire. As in the fields of education, health and the liberal arts more generally, practitioners were being invited to see themselves not simply as teachers but as practitioner researchers, an identity shift mobilized by both the carrot of more knowing practice and the stick of quality audit. As a result, the first decade of the century was characterized by a growing number of studies that, while still small in scale like those of the previous century, were nevertheless better grounded in terms of method, and so more credible as scholarly narratives about the state of the art of music education. Studies such as those reported by Barrett (2006), Bennett (2008), Carey (2008), Gaunt (2007, 2009), Kruger (2000), Nerland (2007), and Presland (2005) draw on a range of qualitative methods - case studies, interviews, participant observation, perception questionnaires - to inquire into the nature of the conservatoire not simply as a performative space but as a learning community.

Some attempts were also made to look beyond a single institution in order to discern more general trends in the field. Mills and Smith's (2003) study of the beliefs of 134 local education authority music teachers in the UK, Mills's (2006) questionnaire probing the beliefs of 61 music students and Purser's (2005) interview-based study of 138 teachers in UK conservatoires, are all moves to canvas a wider terrain of practice than the home institution. Such studies, when taken together those of with pedagogical 'cases' bounded by a singular institution, provide a powerful impetus to re-visit Persson's (1994, 1996b) insistence on distinguishing the 'formidable artist' from the 'formidable pedagogue'. They begin to pry apart what counts as teaching excellence from performative excellence, not in order to create a binary formulation of artistry-orpedagogy, but to foreground the idea that learning theory and pedagogical method are of as much value to the conservatoire as they are to all other formal learning environments. 
It is useful, at this point, to be reminded of two specific propositions in Persson's (1994) earlier work about the cultural impediments that bedevilled research in one-to-one teaching within conservatoires two decades ago, because they are likely to continue to do so, notwithstanding the press of the audit culture and the growing interest in teaching improvement. The first is his insistence that ' $[\mathrm{a}] \mathrm{rt}$ and music ... tend to be fields of interest which are often left unchallenged by anyone who is not a member of the musical community by means of being a qualified musician' (1994, p. 89). The second is that the sort of 'scientific effort' associated with research enquiry is often perceived as opposed to artistic effort, 'since scientific behaviour in the quest for objective generality by its methods poses a potential threat to the individuality of a performing musician' (ibid).

It is both a strength and a limitation of institutional cultures, and particularly ones that are self-consciously at the cutting edge of artistic practice, that they are not readily overturned. With the high stakes that attend any conservatoire, there is much to be lost in following fads and fashions, no matter how compelling they may seem in terms of a rationale for wide and deep change. On the other hand, the tendency to maintain timehonoured practices that continue to be exempted from scrutiny for the reasons Persson foregrounds, is a tendency that is increasingly unsustainable in the context of demands for more client-oriented accountability from higher education institutions.

\section{Developing a project}

So where to next? It would seem reasonable to pursue a second generation of research that is both able to acknowledge and value the teacher-performer and yet can rigorously probe for evidence that the learning opportunities being provided for conservatoire 'clients' are being informed by sound pedagogical theory and practice. In other words, the challenge is to develop a means by which the distinction between 'formidable artist[s]' and 'formidable pedagogue[s]' can be better understood in order better to serve the conservatoire as a learning community. This will take an approach that can simultaneously move in close to, and broaden, the picture of pedagogical practice in the conservatoire. The next generation of research therefore needs to be capable of patient documentation (Sontag, 1966) of intimate pedagogies, re-presenting them in ways that are meaningful both within the conservatoire culture and to a wider higher education community, and also to show how these are both like and unlike more general shifts in pedagogical practice, such as those that are increasingly reliant on digital technologies.

Our view is that that pedagogical capacity-building needs scholarship based on authentic classroom research of the sort that can make the actual daily work of teaching visible both within and beyond the classroom. One such approach, advanced by Peter Taylor and colleagues (Kwek et al, 2010; Taylor, 2012; Taylor et al, 2012), involves the development of site-specific schemes that code videographic data of classroom pedagogical practices. This work, at its core, is an attempt to discover and document teaching practices and their variations.

The development and use of such schemes reflect four principles. First, the schemes should focus on what is important to student learning in each site. Their development creates a context where the explication and clarification of those foci are themselves valuable outcomes. Second, while they necessarily privilege teacher behaviour, the representations of these foci also address relational issues, and therefore can describe specific contributions of one-to-one teaching factors to the development of 
conservatoires as communities of learners. Third, the description of behaviour necessitated in the characterization of differences in specific practices can help make teaching visible. As a consequence, teachers can be assisted to 'see' alternative strategies, and encouraged to make use of them. Finally, such schemes can be used to promote professional growth for teachers. This is not to imply that they represent a panacea, but they do offer a potentially valuable avenue for professional development, one welcomed by participant teachers for its practicality as well as its authenticity.

The performance of such research will need more of the small-scale, wellgrounded studies of the last decade, but they will need to be framed within a shared and authentic 'bottom-up' language, so that the field can be readied for growing investment in large-scale comparative studies that are both rigorous and mutually informative. The pedagogical research approach of Taylor et al (2012) may be useful for this purpose, given that it is a methodology that works with and for, rather simply on or about, institutional teaching as a learning community.

Grounded in these understandings, a research project is underway at one institution to encourage a 'discovery and documentation' of the fundamental purposes and procedures of one-to-one music teaching, and the assumptions behind this timehonored practice. It aims to identify and disseminate empirical evidence about the core learning and teaching transactions of one-to-one pedagogy, in an attempt to structure a reflective exploration of how we might teach more effectively. The authors believe that the project's approach and methods are already potentially transferrable across institutions and pedagogical contexts, and the need to activate this transferability is pressing for reasons outlined above. Thus, with the aim of making such a project implementable in similar and diverse contexts in the near future, the remainder of this paper details one possible approach to characterizing the value of one-to-one pedagogy. Results of the study will be presented in future publications (see also Carey, Lebler \& Gall, 2012).

\section{Building a collaborative approach}

The first piloting of this approach is being conducted within one Australian conservatoire, which has a total enrolment of over 600 undergraduate students in the core areas of performance, composition and pedagogy. A key feature of research design for this project is the cross-disciplinary nature of the research team. Five researchers are involved, two internal and three external to the institution in question. The three external members of the team are from the disciplines of education and the creative industries, one with considerable expertise in quantitative arts research. Of the two internal researchers, one is a full-time member of staff with extensive experience in pedagogical research and one-to-one teaching, and the other, a senior academic with a substantial research record in learning and teaching. It was felt that the diverse experience of team members would enrich the study, particularly in terms of the balance between the insider and outsider perspectives.

The research team meets regularly to discuss and debate issues related to one-toone pedagogy. The meetings are informal, last two to three hours, and are organized and facilitated by the lead internal researcher. Detailed notes are made and emailed to all researchers for discussion at subsequent meetings. Investing in this time together as researchers has enabled the team to develop a research approach that is 'fluid, 
unconscious, and implicitly appropriate', one that allows research choices to be creative, to grow, change and develop (Elmesky, 2005).

Most first-generation research studies on one-to-one pedagogical practices have drawn only on secondary data, such as interviews with teachers and students. In addition to collecting and analyzing such data, this study involves direct examination of one-toone interactions through videographic analysis, in order to map how interactions between teacher and student occur. The intention is to identify and characterize these observed practices and from there, to develop a comprehensive scheme to explore and systematically analyze relational aspects in this method of teaching (an ongoing process).

\section{Implementation}

The project involves four key phases: engagement with teachers; video recording of oneto-one lessons; student generated data and follow up interviews with teachers. These are explored in detail below.

\section{Phase 1: Engagement with teachers}

The tension between the 'maestro performer' and the 'maestro teacher' (Persson, 1994, 1996a) alludes to the imperfect reality that as performers, teachers are not always sharply aware of their pedagogical practices; nor do they always have the language or the tools to articulate their performance practices to students, or their pedagogical practices to researchers or interested others. The project therefore not only presents the opportunity to engage teaching staff at a research level, but also encourages teachers to critically engage with their own pedagogical practices.

One of the rationales for this project was to enable teachers, through collecting evidence on their pedagogical practices, to 'chair' the ongoing vigorous political conversations surrounding the value of one-to-one teaching. Thus, the consideration of 'voice' was the primary driver of the decision to work with teachers not just as research subjects, but as active participants in designing and implementing the research. In this regard, Hallum's (2011) observations on the nature of beneficial partnerships in music education might be invoked to suggest characteristics of effective partnerships between the researchers and teacher-participants: among other things, they are built on good communication, time, trust, and clear roles and responsibility; they take account of context; and they result from careful planning and evaluation.

In her work with teaching staff, Gaunt observes the potential reluctance and 'general skepticism of participants about research relating to teaching and learning, and fear of participation impacting negatively on the relationship of trust between teacher and student' (2007; 2011, p. 164). Probable secondary benefits of this collaborative approach with teachers, then - hard to measure, easier to sense - are an increased willingness of teachers to participate in the research, and the sense of research ownership and control by those teachers who become 'subjects' for the purposes of the interviews and videorecordings.

For this reason, it is important to include teachers from across all performance specialisms within the institution (keyboard, strings, vocal, woodwind, brass and percussion), providing them with adequate information outlining the aim and intention of the study, and the opportunity to discuss with the researchers any ideas or issues of concern they might have (Carey, Lebler \& Gall, in press). 
Phase 2: Video recording of one-to-one lessons

The rationale to capture data through video recording in this second phase of the study is to enable the researchers to directly study interactions between teacher and student, in order to inform and develop the method of analysis in the next phase. The use of video footage has substantial precedent in music education research. Decades ago, Gustafson (1986) analyzed video footage of lessons with a focus on factors that may influence behaviours and interactions; a number of further studies have followed since (e.g. Bowman, 1999; DuFon, 2002, Kennell, 2002; Rostvall \& West, 2003; Young et al, 2003). In a detailed study that used video footage to compare piano teaching in one-toone and group settings, Daniel noted some challenges with the method, including the particularly time-consuming and demanding nature of analysis procedures (2006, p. 193). However, benefits are many, including the opportunity for retrospective and repeated analysis from several researchers, potentially increasing reliability of the analysis (p. 193). A further advantage of video-recording, especially if carried out by the teacher using a small mounted recorder left running in a corner of the room (as in this study), is the relative unobtrusiveness of the process: it obviates the need for a third party (researcher or recording staff) in the intimate space of the teaching studio.

The collection of videographic data involves the use of an unobtrusive, inexpensive, high-quality video recorder (the Zoom Q3 Hand Held Video Recorder), which is relatively simple to operate. The recording process includes emailing the technology department to request a video recorder at a specified date and time; choosing the most appropriate positioning of the camera with the technologist; and documenting participant details including location, date and time (Carey, Lebler \& Gall, in press).

\section{Phase 3: Student-generated data}

Kurkul (2007) highlights the importance of working with both students and teachers in evaluation, for the reason that feedback rarely correlates between these two groups, and Gaunt (2011) observes that students and teachers characterize their relationship differently. The purpose of Phase 3, therefore, is not only to give students a direct voice in the research, but to also allow triangulation of this voice with data from other phases.

Though focus groups are relatively uncommon in studies of one-to-one teaching, they are not unknown; Mills employed them to investigate the beliefs and experiences as instrumental teachers of conservatoire students, for example (2002, 2006). The method of focus groups provides students with a reasonably non-threatening environment in which to express their opinions, as well as giving them the opportunity to immediately react to and reflect upon the views of their peers.

Possible topics in the focus groups include students' personal history with one-toone teaching; the nature of one-to-one teaching; the nature of the teacher-student relationship; the role of gender in that relationship; the teacher as personal and professional role model; the role of the teacher to educate the student for a career as a professional musician (Gaunt, 2011); the perceived importance of the teacher tailoring lessons for each learner (Persson, 1994); and the characteristics and benefits of one-toone versus group teaching (Daniel, 2006). The following questions may be used as stimulus for discussion: 
- What words would you use to describe your experience of one-to-one learning?

- Are there particular things that you find helpful in one-to-one?

- Are there particular things that you find challenging about one-to-one?

- Can you describe the nature of your relationship with your teacher?

- Is there a particular person you have really enjoyed being taught by? What is it about their teaching you found helpful or valuable?

- Is there a particular person you would really like to be taught by? What do you know about them that makes them of interest to you as a teacher?

Phase 4: Follow-up interviews with teachers

Improving practice of one-to-one teaching demands a commitment not only to developing a new research model, but to deep and sustained conversations with those involved. It is therefore important to organize a follow-up meeting involving researchers and teacher-participants, in order to discuss the scheme being used to characterize the observed one-to-one pedagogical practices. This allows participants to clarify the scheme and give their feedback on it as a work-in-progress. Additionally, it enables the researchers to refine the categories of the scheme. Teachers will be subsequently invited to meet individually with the researchers to explore data specifically relating to their own pedagogical practice.

The four phases are summarized in Table 1.

Table 1. Data collection phases for investigation of one-to-one conservatoire teaching

\begin{tabular}{|c|c|c|c|c|}
\hline Phase & $\begin{array}{l}\text { Participant size in } \\
\text { current iteration }\end{array}$ & $\begin{array}{l}\text { Data } \\
\text { collection } \\
\text { method }\end{array}$ & $\begin{array}{l}\text { Data } \\
\text { collected in } \\
\text { current } \\
\text { iteration }\end{array}$ & Data analysis method \\
\hline 1 & $\begin{array}{l}\text { Full-time and part- } \\
\text { time instrumental } \\
\text { and vocal teachers }\end{array}$ & $\begin{array}{l}\text { Informal } \\
\text { interviews }\end{array}$ & $\begin{array}{l}\text { Audio- } \\
\text { recordings } \\
\text { and } \\
\text { transcripts of } \\
\text { interviews }\end{array}$ & $\begin{array}{l}\text { Thematic analysis of } \\
\text { interview transcriptions }\end{array}$ \\
\hline 2 & $\begin{array}{l}\text { Phase } 1 \\
\text { participants plus } \\
\text { students }\end{array}$ & $\begin{array}{l}\text { Video } \\
\text { recording of } \\
\text { one-on-one } \\
\text { lessons }\end{array}$ & $\begin{array}{l}\text { Video- } \\
\text { recordings of } \\
\text { one-to-one } \\
\text { lessons }\end{array}$ & $\begin{array}{l}\text { Coding of videographic } \\
\text { data according to } \\
\text { scheme outlined in } \\
\text { Taylor et al (2012); } \\
\text { cross-analysis with all } \\
\text { other phases }\end{array}$ \\
\hline 3 & $\begin{array}{l}\text { Undergraduate and } \\
\text { postgraduate } \\
\text { instrumental and } \\
\text { vocal students }\end{array}$ & Focus groups & $\begin{array}{l}\text { Audio- } \\
\text { recordings } \\
\text { and } \\
\text { transcripts of }\end{array}$ & $\begin{array}{l}\text { Thematic analysis of } \\
\text { focus group } \\
\text { transcriptions; cross- } \\
\text { analysis with Phases } 1\end{array}$ \\
\hline
\end{tabular}


focus groups

Audiorecordings

and transcripts of interviews and 4

Thematic analysis of interview transcriptions and cross-analysis with Phases 1 and 3

informal
interviews

\section{Closing remarks}

Music learning and teaching practices which may have been historically appropriate are now in question (Fautley, 2010, p. 1), and in the current challenging higher education environment, the logic that one-to-one teaching is necessary due to its centuries of precedent fails to withstand scrutiny. The reality that 'one-on-one teaching does not inspire us to question how we teach' (Chronister, 2005, p. 8) only heightens the need to systematically investigate our pedagogical practices and processes. Pressing aims for one-to-one teaching in the conservatoire then, include a need 'to consider the relational aspects of one-to-one tuition in more detail, building the research evidence base, . . . and enabling staff development' (Gaunt, 2011, p. 177). The process of developing a way to characterize individual music tuition, such as that described in this paper, represents an opportunity to build this evidence-base, reflect on and explore current practices and processes of learning and teaching, and to put new understandings that result from this research to improve pedagogical practices and student learning in the conservatoire environment.

The driving intention behind the methodology detailed in this paper is to improve understanding of the learning transactions that occur in the one-to-one environment, in order that such understanding may then be utilized by teachers to enhance their own practice, and in turn increase the effectiveness of student learning. The next stages of this research will systematically assess the approach described here for its ability to improve teaching practices in the conservatoire setting. As these stages progress, the project methodology will be continually evaluated for workability, applicability, and transferability to other institutions and other one-on-one pedagogical contexts (for example, doctoral supervision, whose significant similarities to individual music tuition has been noted by several researchers, e.g. Gaunt, 2011; Harrison, 2012). This critical reflection and evaluation will inform future iterations of the research, so that the methodology develops in the continuous cycle of growth, implementation, review and improvement that is characteristic of qualitative research.

In this way, the authors hope this project will fulfill its aims: to assist institutions justify the need for and value of one-to-one teaching, to heighten teachers' self-awareness and understanding of their pedagogical approach, and ultimately to provide students with a higher-quality and more effective learning environment.

\section{References}

Abeles, H. F. (1975). Student perceptions of characteristic of effective applied music instructors. Journal of Research in Music Education, 23(2), 147-154. 
Barnett, R. (1997). Higher education: A critical business. Milton Keynes: Open University Press/SRHE.

Barrett, M. (2006). Creative collaboration: An 'eminence' study of teaching and learning in music composition. Psychology of Music, 34(2), 195-218.

Bennett, D. (2008). Portfolio careers and the conservatoire. In D. Bennett \& M. Hannan (Eds.), Inside Outside Downside Up: Conservatoire Training and Musicians' Work: (pp. 61-72). Perth: Black Swan Press.

Bowman, M. (1994). Using video in research. Spotlights. Retrieved 17 July, 2012, from http://www.sfu.ca/media-lab/cmns362/Spotlight45.pdf

Brand, M. (1984). Music teacher effectiveness research. Houston, TX: University of Houston Press.

Bunting, R. (1987). Composing music: Case studies in the teaching and learning process. British Journal of Music Education, 4(1), 25-52.

Burnard, P. (2006). Telling half the story: Making explicit the significance of methods and methodologies in music education research. Music Education Research, 8(2), 143-152.

Burwell, K. (2005). A degree of independence: Teachers' approaches to instrumental tuition in a university college. British Journal of Music Education, 22(3), 199-215.

Burwell, K. (2006). On musicians and singers: An investigation of different approaches taken by vocal and instrumental teachers in higher education. Music Education Research, 8(3), 331-347.

Burwell, K., Young, V., \& Pickup, D. (2003). Taking the lead: The development of the student as reflective practitioner in instrumental lessons at H.E. level. RIME Conference, Exeter University, Exeter.

Carey, G. (2008). New understanding of 'relevant' keyboard pedagogy in tertiary institutions. Saarbrucken, Germany: Verlag Dr. Muller (VDM).

Carey, G., Lebler, D. \& Gall, S. (in press). Investigating the one-to-one teaching model in higher music education: Developing a collaborative model of inquiry. Scientia Paedagogica Experimentali:International Journal of Experimental Research in Education. Accepted for publication November, 2011.

Chronister, R. (2005). Principles of teaching and learning. In Chronister, R. \& Darling, E., A piano teacher's legacy: Selected writings by Richard Chronister, 7-28. Kingston, NJ: Frances Clark Center for Keyboard Pedagogy.

Daniel, R. (2006). Exploring music instrument teaching and learning environments: Video analysis as a means of elucidating process and learning outcomes. Music Education Research, 8(2), 191-215.

Dufon, J. (2002). Video recording in ethnographic SLA research: Some issues of validity in data collection. Language Learning and Technology, 6(1), 40-59.

Elmesky, R. (2005). Rethinking qualitative research: Research participants as central researchers and enacting ethical practices as habitus [20 Paragraphs]. In Forum: Qualitative Social Research, 6(3), Art 36.

Fautley, M. (2010). Assessment in music education. Oxford: Oxford University Press.

Gaunt, H. (2007). One-to-one tuition in a conservatoire: The perceptions of instrumental and vocal teachers. Psychology of Music 36(2), 215-245. 
Gaunt, H. (2009). One-to-one tuition in a conservatoire: The perceptions of instrumental and vocal students. Psychology of Music 38(2), 178-208.

Gaunt, H. (2011). Understanding the one-to-one relationship in instrumental/vocal tuition in Higher Education: Comparing student and teacher perceptions. British Journal of Music Education 28(2), 159-179.

Gewirtz, S. (1999). Efficiency at any cost: The post-welfarist education policy context. In C. Symes and D. Meadmore (Eds.), The extra-ordinary school: Parergonality and pedagogy. New York: Peter Lang, 129-147.

Gustafson, R. I. (1986). Effects of interpersonal dynamics in the student-teacher dyads on diagnostic and remedial content of four private violin lessons. Psychology of Music 14, 130-139.

Hallum, R. (2011). Effective partnership working in music education: Principles and practice. International Journal of Music Education, 29(2), 155-171.

Harrison, S. D. (2004). Lifelong learning in music education: A brief examination. In D. Roebuck, J. Searle \& C. McKavanagh (Eds.), Doing, thinking, activity, learning: Proceedings of the 12th Annual International Conference on Post-compulsory Education and Training 1, 204-208. Brisbane: Australian Academic Press.

Harrison, S. D. (2012). Letting go: An auto-ethnography of supervising the research higher degree in music. International Journal of Music Education, 30(2), 99-110.

Kennell, R. (2002). Systematic research in studio instruction in music. In R. Colwell \& C. Richardson (Eds.), The new handbook of research on music teaching and learning, New York, Oxford, 243-256.

Kostka, M. J. (1984). An investigation of reinforcements, time use, and student attentiveness in piano lessons. Journal of Research in Music Education 32(2), 113-122.

Kruger, T. (2000). Teacher practice, pedagogical discourses and the construction of knowledge: Two case studies of teachers at work. Bergen: Bergen University Press.

Kurkul, W. W. (2007). Nonverbal communication in one-to-one music performance instruction. Psychology of Music 35(2), 327-352.

Kwek, D., Taylor, P.G., Foo, A., Tan, C. \& Wong H.M. (2010). Pedagogy for 21st century learning: Raffles programme coding scheme. Singapore: Office of Education Research, National Institute of Education.

Lather, P. (2007). Getting lost: Feminist efforts toward a double(d) science. Albany: State University of New York Press.

Lawson, A. (1999). From West to waste through dirty data. Campus Review, April 7-13: 11.

Mills, J. (2002). Conservatoire students’ perceptions of the characteristics of effective instrumental and vocal tuition. Bulletin of the Council for Research in Music Education, 153/154, 78-82.

Mills, J. (2006). Performing and teaching: The beliefs and experience of music students as instrumental teachers. Psychology of Music 34(3), 372-390.

Mills, J., \& Smith, J. (2003). Teachers' beliefs about effective instrumental teaching in schools and higher education. British Journal of Music Education 20(1), 5-27.

Nerland, M. (2007). One-to-one teaching as cultural practice: Two case studies from an academy of music. Music Education Research, 9(3), 399-416. 
Persson, R. (1994). Concert musicians as teachers: On good intentions falling short. European Journal for High Ability 5, 79-91.

Persson, R. (1996a). Brilliant performers as teachers: A case study of commonsense teaching in a conservatoire setting. International Journal of Music Education, 28, 25-36.

Persson, R. (1996b). Studying with a musical maestro: A case study of commonsense teaching in artistic training. Creativity Research Journal 9(1), 33-46.

Presland, C. (2005). Conservatoire student and instrumental professor: The student perspective on a complex relationship. British Journal of Music Education, 22(3), 237-248.

Purser, D. (2005). Performers as teachers: Exploring the teaching approaches of instrumental teachers in conservatoires. British Journal of Music Education, 22, 287-298.

Rostvall, A-L. \& West, T. (2003). Analysis of interaction and learning in instrumental teaching. Music Education Research, 5(3), 213-226.

Schmidt, C. P. (1989). Individual differences in perception of applied music teaching feedback. Psychology of Music, 17(2), 110-112.

Schmidt, C. P. (1992). Systematic research in applied music instruction. Quarterly Journal of Music Teaching and Learning 3(2), 32-45.

Sontag, S. (1966). Against interpretation: And other essays. New York: Penguin.

Strathern, M. (1997). 'Improving ratings': Audit in the British University system. European Review, 5(3), 305-321.

Strathern, M. (2000). The tyranny of transparency. British Educational Research Journal, 26(3), 310-323.

Taylor, P.G. (2012). BGS Tablet Pedagogical Practices project: Final report. Unpublished report. Brisbane, Australia: Brisbane Grammar School.

Taylor, P.G., Kwek, D., Tan, C. \& Short, B. (2012). Coding of classroom pedagogical practices: An international comparison. Paper submitted for publication.

Young, V., Burwell, K. \& Pickup, D. (2003). Areas of study and teaching strategies in instrumental teaching: A case study research project. Music Education Research, 5(2), 139-155.

\section{Authors}

Gemma Carey is Senior Lecturer in Piano and Head of Pedagogy at the Queensland Conservatorium Griffith University. Gemma's expertise and research interests are in the area of Performance Pedagogy, Curriculum and Teaching and Learning. She has presented and published papers in the field of Instrumental Pedagogy both nationally and internationally and works with students from pre-tertiary to doctoral level.

Catherine Grant is Research Fellow and Associate at the Queensland Conservatorium Research Centre, Griffith University. Her research interests lie in the areas of health and wellbeing for performing artists, tertiary music teaching and learning, and the sustainability of music genres. Current research includes an investigation of collaborative-piano pedagogy in the tertiary environment. 
Erica McWilliam is an Adjunct Professor in the Centre of Excellence for Creative Industries and Innovation in the Creative Industries Faculty of the Queensland University of Technology. She has a prolific record of publication in teaching and learning across all sectors of education, from early childhood to doctoral studies, and is a Fellow of the Australian College of Educators and an Associate Fellow of the Australian Learning and Teaching Council.

Peter Taylor is an Adjunct Professor at Griffith University (Australia), having recently worked as a Professor in the Centre for Research in Pedagogy and Practice at Singapore's National Institute of Education. His most recent research has given rise to methodology for characterising pedagogical practices across a range of national and international sites and systems. 